\title{
A retrospective study of endometrial histopathology in abnormal uterine bleeding patients
}

\author{
Neha Varun*, Nidhi Gupta, Sana Khan
}

\begin{abstract}
Department of Obstetrics and Gynecology, Hamdard Institute of Medical Sciences and Research, Jamia Hamdard
\end{abstract} University, Delhi, India

Received: 31 July 2018

Accepted: 29 August 2018

\author{
*Correspondence: \\ Dr. Neha Varun, \\ E-mail: drneha.himsr@gmail.com
}

Copyright: (c) the author(s), publisher and licensee Medip Academy. This is an open-access article distributed under the terms of the Creative Commons Attribution Non-Commercial License, which permits unrestricted non-commercial use, distribution, and reproduction in any medium, provided the original work is properly cited.

\begin{abstract}
Background: Abnormal uterine bleeding (AUB) is one of the most commonly encountered gynecological problem and almost $33 \%$ of women in gynecological outpatient department presented with abnormal uterine bleeding. Dilatation and curettage (D and C) have been the main diagnostic procedure in the evaluation of abnormal uterine bleeding patients for decades. The objective of the present study was to analyze the different types of endometrial histopathology of patients presented with the abnormal uterine bleeding and its correlation with the different types of abnormal uterine bleeding

Methods: This is a retrospective study, conducted in a medical college in the Department of Obstetrics and Gynecology over a period of one year from June '17 to June '18. All cases of AUB more than 35 years of the age group who underwent $\mathrm{D}$ and $\mathrm{C}$ procedure were included in this study. Total 100 patients were analyzed.

Results: Total 100 patients were analyzed. Age group ranges from 35-58 years and most common age group presenting with AUB was 35-39 years. The most common presenting complaint was menorrhagia 54\% (54/100). Histopathology of endometrium showed non-organic causes in $80 \%(80 / 100)$ of AUB patients and the remaining $20 \%$ (20/100) had organic causes. Most common endometrial histopathology among non-organic causes was proliferative endometrium $43.75 \%$ (35/80) and the most common organic cause was endometrial polyp 40\% (8/20). Endometrial hyperplasia was found in $30 \%(6 / 20)$ and endometrial carcinoma was found in $20 \%(4 / 20)$ of cases among organic causes.

Conclusions: $\mathrm{D}$ and $\mathrm{C}$ is the useful and the cost-effective diagnostic procedure in the evaluation of AUB. Histopathological evaluation of endometrial samples is especially indicated in AUB patients to rule out carcinoma and preneoplastic conditions as histopathology is $100 \%$ diagnostic in cases of endometrial hyperplasia and carcinoma.
\end{abstract}

Keywords: Abnormal uterine bleeding, Dilatation and curettage, Histopathology

\section{INTRODUCTION}

Abnormal uterine bleeding is defined as any abnormality in the bleeding pattern in terms of frequency, duration, amount and cyclicity. ${ }^{1}$ It includes both the non-organic and organic causes (structural) of endometrium. Abnormal uterine bleeding (AUB) is the most commonly encountered Gynecological problem and almost $33 \%$ of women in Gynecological outpatient department presented with abnormal uterine bleeding and incidence rises in peri- and postmenopausal women. This condition has enormous consequences with regard to social life, clinical workload and morbidity. ${ }^{2}$ Endometrial carcinomas may clinically present as AUB in $8-50 \%$ of cases. ${ }^{3}$ In perimenopausal and menopausal females who presented with AUB, the risk of endometrial hyperplasia and carcinoma are increased and $\mathrm{D}$ and $\mathrm{C}$ plays an important role in diagnosing these conditions. ${ }^{4}$ The cause of the bleeding 
can be often diagnosed by simple gynecological and speculum examinations. The transvaginal ultrasound is a diagnostic tool which has a low specificity and sensitivity in diagnosing the cause of bleeding. ${ }^{5}$ Dilatation and curettage ( $\mathrm{D}$ and $\mathrm{C}$ ) have been the main diagnostic procedure in the evaluation of abnormal uterine bleeding patients for decades.

The introduction of hysteroscopy opened a new dimension in the evaluation of a patient with abnormal uterine bleeding and it has replaced the D and C procedure as it affords a more accurate diagnosis than D and $\mathrm{C}$ for intrauterine pathologies which are pedunculated but for hyperplasia and carcinoma endometrium, histopathological evaluation of endometrium is $100 \%$ diagnostic, and D and C is costeffective as compared to hysteroscopy.

The aim of this study is to analyze the varied types of histopathology of endometrium in AUB patients and its correlation with the different types of AUB (clinical presentation).

\section{METHODS}

A retrospective analysis including 100 patients was conducted in a medical college in the Department of Obstetrics and Gynecology over a period of one year from June'17 to June '18. Patients, more than 35 years of the age group who presented with an AUB and underwent $\mathrm{D}$ and $\mathrm{C}$ procedure were included in this study. Patients who were on hormonal therapy were excluded from the study. Data regarding the age, presenting complaints, any significant past history, examination findings, ultrasound findings, Intra-operative findings and histopathology report were retrieved from the medical records and were recorded in the structured Performa.

Histopathological findings were divided into two broad categories, AUB due to non-organic and organic causes. Non-organic includes proliferative, secretory, disordered proliferative and atrophic. Organic causes include endometrial carcinoma, tubercular endometritis, endometrial polyp and endometrial hyperplasia. Histopathological findings were correlated with the clinical presentations of the patient.

\section{Statistical analysis}

Statistical package for social sciences (SPSS - Version 20) was used to carry out the statistical analysis of data. The analysis was done in the form of percentages and proportions and represented as tables where necessary.

\section{RESULTS}

Total 100 patients were included in this study. Age group ranges from 35-58 years and most common age group presenting with AUB was 35-39 years 50\% (50/100). In more than 55years group only $2 \%(2 / 100)$ patients were there (Table 1).

Table 1: Distribution of patients according to the age group.

\begin{tabular}{|ll|}
\hline Age group (years) & Number of patients (100) \\
\hline $35-39$ & 50 \\
$40-44$ & 27 \\
\hline $45-49$ & 17 \\
\hline $50-54$ & 4 \\
$\geq 55$ & 2 \\
\hline
\end{tabular}

The most common clinical presentation was menorrhagia in $54 \%$ of cases $(54 / 100)$ followed by polymenorrhagia $12 \%$, metrorrhagia $12 \%$, postmenopausal bleeding $10 \%$, polymenorrhea $8 \%$ and oligomenorrhea $4 \%$ (Table 2 ).

Table 2: Distribution of patients according to the clinical presentation.

\begin{tabular}{|ll|}
\hline Clinical presentation & Number of patients (100) \\
\hline Menorrhagia & 54 \\
\hline Polymenorrhoea & 8 \\
\hline Polymenorrhagia & 12 \\
\hline Postmenopausal bleeding & 10 \\
\hline Metrorrhagia & 12 \\
\hline Oligomenorrhoea & 4 \\
\hline
\end{tabular}

Out of total 100 patients, 80\% (80/100) patients had AUB due to non-organic causes of the endometrium and $20 \%$ (20/100) had organic causes. Among non-organic causes, most common histopathology was proliferative endometrium $43.75 \%(35 / 80)$ and the most common organic cause was endometrial polyp $40 \% \quad(8 / 20)$. Endometrial adenocarcinoma was present in $20 \%(4 / 20)$ of organic causes (Table 3 ).

Table 3: Distribution of patients according to the histopathological findings and organic and nonorganic causes.

\begin{tabular}{|ll|}
\hline Histopathological pattern & $\begin{array}{l}\text { Number of } \\
\text { patients }(100)\end{array}$ \\
\hline Non-organic causes & $80(80 \%)$ \\
\hline Proliferative endometrium & $35(43.75 \%)$ \\
\hline Secretory endometrium & $23(28.75 \%)$ \\
\hline Atrophic endometrium & $10(12.5 \%)$ \\
\hline Disordered proliferative endometrium & $12(15 \%)$ \\
\hline Organic causes & $20(20 \%)$ \\
\hline Endometrial hyperplasia with atypia & $2(10 \%)$ \\
\hline Endometrial hyperplasia without atypia & $4(20 \%)$ \\
\hline Tubercular endometritis & $2(10 \%)$ \\
\hline Endometrial polyp & $8(40 \%)$ \\
\hline Endometrial adenocarcinoma & $4(20 \%)$ \\
\hline
\end{tabular}

When the histopathology of endometrium was correlated with the clinical presentations, menorrhagia (54\%), the most common complaint showed proliferative 
endometrium in $50 \%(27 / 54)$ of cases. Endometrial carcinoma $(4 \%)$ presented as menorrhagia in $50 \%(2 / 4)$ of cases and postmenopausal bleeding in the remaining $50 \%(2 / 4)$ of cases. (Table 4$)$

Table 4: Distribution of patients according to clinical presentation and histopathological findings.

\begin{tabular}{|c|c|c|c|c|c|c|c|c|c|}
\hline & Histopathog. & & & & & & & & Total \\
\hline Clinical features & Proliferative & Secretory & $\begin{array}{l}\text { Disordered } \\
\text { proliferative }\end{array}$ & Atrophic & $\begin{array}{l}\text { Endometrial } \\
\text { hyperplasia }\end{array}$ & Tubercular & Polyp & Carcinoma & \\
\hline Menorrhagia & 27 & 15 & 3 & - & 4 & - & 3 & 2 & 54 \\
\hline Polymenorrhoea & - & 2 & 1 & 5 & - & - & - & - & 8 \\
\hline Metrorrhagia & 2 & 3 & 4 & - & - & - & 3 & - & 12 \\
\hline $\begin{array}{l}\text { Postmenopausal } \\
\text { bleeding }\end{array}$ & 2 & 1 & - & 2 & 2 & - & 1 & 2 & 10 \\
\hline Oligomenorrhoea & - & - & - & 2 & - & 2 & - & - & 4 \\
\hline Polymenorrhagia & 4 & 2 & 4 & 1 & - & - & 1 & - & 12 \\
\hline Total & 35 & 23 & 12 & 10 & 6 & 2 & 8 & 4 & 100 \\
\hline
\end{tabular}

\section{DISCUSSION}

Abnormal uterine bleeding is the common problem among gynecological patients and it has been determined that approximately $6 \%$ of women in reproductive age group visit OPD due to excessive menstrual loss every year. ${ }^{6}$ AUB is of concern because it may have medical and social repercussion, as excessive bleeding may cause interference in daily activities and sexual life. AUB needs a complete evaluation by the combination of physical examination, ultrasound findings and histopathological diagnosis. ${ }^{7}$ Majority of AUB cases had benign pathology on histopathological evaluation, so histopathology of the endometrium is an important parameter for a restrictive approach, in order to avoid unnecessary hysterectomies. Endometrial assessment is important for the diagnosis of endometrial carcinoma and preneoplastic conditions, in which histopathology is $100 \%$ diagnostic and a gold standard investigation. It is also required in patients where bleeding is not improving after medical therapy. ${ }^{6}$

A total of 100 endometrial samples of AUB patients were analyzed. Maximum patients were in 35-39 years of age group. Age was an important factor as the age advances more progressive lesions were found in histopathology as compared to the reproductive age group. The most common presenting complaint in this study was menorrhagia (54\%) and results are similar to the study conducted by Verma et al with the similar sample size of 100 patients, this study showed menorrhagia as the most common complaint in $57 \%$ of cases. Jairapuri et al also showed similar results, menorrhagia as the most common complaint (41\%). ${ }^{8,9}$ Out of 100 histopathology's, $80 \%$ showed benign non-organic endometrial cause and remaining $20 \%$ showed organic cause which is comparable with the study conducted by Gon et al which showed non-organic causes in $80.01 \%$ and organic pathology in $19.01 \%$ of cases. $^{3}$

Most common histopathology among non-organic causes was proliferative endometrium (35\%) which is comparable with the study by Ghani et al and most common organic pathology was endometrial polyp (8\%) which is similar to the study conducted by Gon et al which showed endometrial polyp in $8.6 \%$ of total cases as the commonest organic pathology. 3,10

Gon et al showed endometrial carcinoma in 4.6\% (7/151) of cases and $42.8 \%$ (3/7) were found in patients presented with the postmenopausal bleeding and remaining $57.1 \%$ $(4 / 7)$ in patients with menometrorrhagia. Similar results were found in present study, carcinoma in 4\% (4/100) of cases and $50 \%(2 / 4)$ in postmenopausal bleeding and $50 \%(2 / 4)$ in menorrhagia cases. Shrestha et al also showed that endometrial carcinoma is most commonly found in postmenopausal age group. ${ }^{11}$

So, histopathological diagnosis of endometrium in AUB patients is an important and a necessary investigation for appropriate planning of optimal treatment in these patients and to prevent the development of endometrial carcinoma. $^{12}$ AUB in perimenopausal and postmenopausal patients is alarming and needs meticulous evaluation because it could be the only clinical symptom of endometrial carcinoma and preneoplastic conditions in these patients.

\section{CONCLUSION}

$\mathrm{D}$ and $\mathrm{C}$ is the useful and the cost-effective diagnostic procedure in the evaluation of AUB. Menorrhagia is the most common presenting complaint among AUB patients. Histopathology of the endometrium is especially recommended in AUB patients to rule out carcinoma and preneoplastic conditions as the histopathology is $100 \%$ diagnostic in these cases. This particular study establishes the good diagnostic yield of dilatation and curettage in AUB patients.

\section{Funding: No funding sources Conflict of interest: None declared}


Ethical approval: The study was approved by the Institutional Ethics Committee

\section{REFERENCES}

1. Munro MG, Critchley HO, Fraser IS, FIGO Menstrual Disorders Working Group. The FIGO classification of causes of abnormal uterine bleeding in the reproductive years. Fertil Steril 2011;95(7):2204-8.

2. The ESHRE Capri workshop group. Endometrial bleeding. Human reproduction update 2007;13(5): 421-31.

3. Gon S, Kundu T, Mallick D, Ghosh G. A Study on Histopathological Patterns of Endometrium in Different Types of Abnormal Uterine Bleeding Among Peri and Postmenopausal Women. IOSR J Dent Med Sci. 2016;15(9):106-111

4. Kumar A, Mittal S. Endometrial sampling: How? and why? Obstet Gynae Today. 2007;12(6):284-7.

5. Breijer M, Timemermans A, Van Doorn H, Mol J. Diagnostic strategies for postmenopausal bleeding. Obstet Gynecol Int. 2010;5.

6. Abid M, Hashmi AA, Malik B, Haroon S, Faridi N, Edhi MM. Clinical pattern and spectrum of endometrial pathologies in patients with abnormal uterine bleeding in Pakistan: need to adopt a more conservative approach to treatment. BMC Women's Health. 2014;14(1):132.

7. Gupta A, Rathore AM, Manaktala U, Rudingwa P. Evaluation and histopathological correlation of abnormal uterine bleeding in perimenopausal women. Int J Biomed Adv Res. 2013;4(8):509-13

8. Verma D, Verma A. Histopathological correlation of abnormal uterine bleeding in perimenopausal women. Int J Reprod Contracept Obstet Gynecol. 2016;5(7):2343-5.

9. Jairapuri ZS, Rana S, Jeteley S. Atypical uterine bleeding-histopathological audit of endometrium: a study of 638 cases. Al Ameen J Med Sci. 2013;6(1):21-8.

10. Ghani NA, Razak AA, Abdullah EM. Abnormal uterine bleeding: a histopathological study. World Res J Clinical Pathol. 2012:1(1);06-8.

11. Shrestha S, Sigdel B. Study of endometrial status of patients with abnormal uterine bleeding in patan hospital. J Coll Med Sci. 2013;9(2):20-4.

12. Ørbo A, Arnes M, Hancke C, Vereide A, Pettersen I, Larsen K. Treatment results of endometrial hyperplasia after prospective D-score classification: a follow-up study comparing effect of LNG-IUD and oral progestins versus observation only. Gynecol Oncol. 2008;111(1):68-73.

Cite this article as: Varun N, Gupta N, Khan S. A retrospective study of endometrial histopathology in abnormal uterine bleeding patients. Int J Reprod Contracept Obstet Gynecol 2018;7:4116-9. 